\title{
Romantic Attachment and Subtypes/Dimensions of Jealousy
}

\author{
Donatella Marazziti*, Giorgio Consoli, Francesco Albanese, Emanuela Laquidara, Stefano Baroni, \\ Mario Catena Dell'Osso
}

Dipartimento di Psichiatria, Neurobiologia, Farmacologia e Biotecnologie, University of Pisa, Pisa, Italy

\begin{abstract}
The present study explored the possible relationship between romantic attachment and jealousy in 100 healthy subjects. The romantic attachment and jealousy were evaluated by means of, respectively, the "Experiences in Close Relationships" questionnaire (ECR), and the "Questionario della Gelosia" (QUEGE). The ECR anxiety scale was related to all QUEGE dimensions, while the ECR avoidance scale to three. Individuals with the preoccupied attachment style showed higher scores than secure subjects on the obsessionality, interpersonal sensitivity and fear of loss dimensions. Fearfulavoidant individuals had higher score than secure subjects on the fear of loss dimension only, while dismissing individuals had lower scores on the self-esteem dimension.
\end{abstract}

These findings suggest that romantic attachment and jealousy are intertwined.

Keywords: Romantic attachment, romantic jealousy, experiences in close relationships questionnaire, questionario della gelosia.

\section{INTRODUCTION}

The attachment theory was developed by Bowlby in the late sixties and along the next decades [1-3]. According to him, the attachment process begins and is set up during early years, through the formation of emotional ties between the infant and primary caregivers [1-5], and it is relatively stable throughout the life $[6,7]$. Not surprisingly, given the evidence of the common features shared by parent-child and adult-adult interactions, the attachment theory was rapidly extended to adult romantic bonding, while highlighting that these last relationships involve the integration of three behavioral systems: attachment, caregiving and sexual mating [8]. Besides similarities, in fact, several differences exist between prototypical adult romantic relationships and infant forms of attachments. Childhood attachments are complementary: a caregiver provides but does not receive care, while adult relationships are usually reciprocal. Moreover, infants may need physical contacts to feel wholly secure, while older children and adults may derive comfort from knowing that the attachment figure exists and is available, if needed. The attachment figure of a child is generally a parent, whereas the attachment figure of an adult individual is most commonly a peer, usually a sexual partner. Therefore, the request of availability from him or her often involves that of exclusivity: for this reason, the possibility of being abandoned and the fear of losing the partner and his/her exclusivity would trigger romantic jealousy, according to some authors [9].

Romantic jealousy is a complex phenomenon that can be defined as "a perception of a threat of loss of a valued relationship to a real or imagined rival" which includes affective,

\footnotetext{
"Address correspondence to this author at the Dipartimento di Psichiatria, Neurobiologia, Farmacologia e Biotecnologie, University of Pisa, Via Roma 67, 56100 Pisa, Italy; Tel: +39 050 2219768; Fax: +39 050 2219787; E-mail: dmarazzi@psico.med.unipi.it
}

cognitive and behavioral components [10]. A wide agreement exists on the notion that it is a heterogeneous condition ranging from normality to pathology, with different degrees of intensity, persistence and insight [11-13].

Romantic jealousy and attachment share some characteristics: both can be interpreted as dynamics aimed at maintaining the subjects/partners together [14], appear to be triggered by the separation from the attachment figure/partner [15], involve the same basic emotions, such as fear, anger, sadness [16], and, finally, both elicit a sense of safety when the other is close and responsive, or the opposite when he or she is distant $[8,17]$.

Traditionally, attachment has been divided into two categories, "secure" and "insecure". Secure attachment is characterized by the expectation of availability and responsiveness from others, and the ability to tolerate and attenuate negative emotions and comfort feelings with intimacy. Insecure attachment has been related to inadequate childhood caregiving, characterized by intrusive, frightening, neglectful, and lacking behaviors. Since the attachment quality seems to be an organizer of emotional and behavioral responses [18], it is worth noting that insecure attachment, although not pathological by itself, has been linked to a greater susceptibility to psychopathological disorders [19-23], and also to somatic diseases [24-26].

Even romantic attachment in adulthood would be strongly influenced by the early attachment process. Following the 4-group model of attachment styles set up by Bartholomew and Horowitz [19] for adult attachment, Brennan and colleagues [27] proposed that romantic attachment would seem to consist of two components, "anxiety" and "avoidance," that, when combined together, would produce four attachment styles: secure, preoccupied, fearful-avoidant and dismissing. Securely-attached individuals are characterized by low anxiety and low avoidance; they feel comfortable when seeking help and intimacy, and they expect sup- 
port from others. Subjects with the preoccupied attachment are characterized by high anxiety and low avoidance and they show an anxious, aroused style of relating, with an excessive fear of loss. Fearfully-avoidant attached subjects are characterized by high anxiety and high avoidance: they are deeply needful of a close relationship and, yet, they avoid any intimacy. Dismissing attached subjects, whose main features are represented by low anxiety and high avoidance, show independence, avoidance of intimacy and distrust of others. Some studies showed that differences in attachment styles seem to influence both the frequency and the patterns of jealousy expression: individuals with the preoccupied or fearful-avoidant attachment styles more often become jealous and consider rivals as more threatening than those with the secure attachment style [9, 28-32]. In addition, preoccupied subjects have been reported to display more negative affect and engage in more surveillance behavior than those with other attachment styles. Dismissing subjects, when jealous, report feeling less sad than secure and preoccupied ones, and less sadness than preoccupied ones [30]. Furthermore, whereas avoidant subjects tend to associate relationships with fear of closeness, preoccupied subjects associate relationships with extreme emotions, strong desire for reciprocation and jealousy [8]. Attachment style also plays an important role in determining which kind of infidelity elicits more jealousy: secure individuals are more likely to find emotional infidelity than sexual infidelity distressful, whereas dismissing individuals are more likely to find sexual infidelity to be the bigger problem [33]. Moreover, persons who display more suspicious jealousy have greater insecurity and anxious or avoidant attachment [34].

However, jealousy is a quite heterogeneous phenomenon, even within the normality domain [35-37], so that it would be more valuable to ascertain the impact of attachment styles on specific jealousy features.

Therefore, given the paucity of information on this topic, the aim of the present study was to explore the possible relationship between some qualitative characteristics of normal jealousy, as assessed by means of a specific instrument, validated in an Italian population, the so-called "Questionario della Gelosia" (QUEGE) [37-39], that permitted to identify five psychopathological dimensions within the jealousy phenomenon, and the romantic attachment scale, evaluated by means of the "Experiences in Close Relationships" questionnaire (ECR) [27].

\section{MATERIALS AND METHODOLOGY}

\section{Subjects}

The study sample included 100 subjects (55 men and 45 women, mean age $34.31 \pm 7.9$ years), recruited amongst the staff of the Police Department of Florence (Italy) and from partners/friends accompanying patients at the outpatient ward of the Dipartimento di Psichiatria, Neurobiologia, Farmacologia e Biotecnologie, University of Pisa, Italy; these last subjects were chosen to match with those coming from the first place. Socio-demographic data, including gender, age, marital status, work status and duration of the relationship were collected using a standardized form. The two samples were quite similar in terms of socio-demographic characteristics and individual features, as shown herein: 30 men and 22 women and 25 men and 23 women were recruited in Florence (subgroup 1) and Pisa (subgroup 2), respectively. As far as the work activity of the subgroup 2 is concerned, 25 were office workers, 15 were university students, eight were managers and three were traders. The educational level was at least 13 years of school (63\% and 67\% in subgroup 1 and 2, respectively), or higher (graduation, $37 \%$ and $33 \%$, respectively). Thirty-eight subjects of the subgroup 1 was married or lived with the same partner since at least one year (length of the relationship, mean \pm SD: $5.4 \pm 4.7$ years), and 12 were single. Thirty-six subjects of the subgroup 2 was married or lived with the same partner since at least one year (length of the relationship, mean \pm SD: $4.8 \pm 4.4$ years), and 14 were single.

All subjects had no family nor personal history of any major psychiatric disorder, as assessed by a psychiatric interview carried out by a senior psychiatrist (DM), by means of the Structured Clinical Interview for DSM-IV Axis I Disorders-Patient Edition (SCID-I/P) [40].

In addition, they were free of any physical illness, as documented by a general check-up and by the normal blood and urine tests, and were psychotropic drug-free; none were heavy smokers or belonged to HIV-risk groups.

Prior to clinical assessment, subjects received a complete description of the study and gave written informed consent for their participation in the study that was approved by the Ethics Committee at Pisa University.

\section{Instruments}

The romantic attachment was assessed by means of the Italian version of the ECR [41], a self- report questionnaire that was developed specifically for measuring romantic attachment [27].

The Italian version proved to have good psychometric properties of validity and reliability [41]. The ECR consists of 36 items, scored on a seven-point Likert scale, with 1 indicating "disagree strongly" and 7 indicating "agree strongly". We used age- and sex- stratified norms obtained in the validation study of the Italian translation. Scores within one standard deviation from the norm were considered as normal. The algorithm for calculating the scores of ECR gives backs a coefficient for the anxiety dimension and one for the avoidance dimension, according to the original model proposed by Brennan and co-workers [27]. According to these coefficients, participants are classified as secure (both anxiety and avoidance low coefficients), preoccupied (high anxiety and low avoidance coefficients), fearful-avoidant (high anxiety and high avoidance coefficients), or dismissing-avoidant (high avoidance and low anxiety coefficients).

The jealousy questionnaire (QUEGE) [37] is a self-report instrument comprising 30 items which explore the presence, frequency and duration of behaviors/feelings related to jealousy; items are scored from 1 to 4 , with 1 denoting their absence and 4 their highest frequency (or duration). The instrument was developed by organizing "a priori" the thirty items in five groups, each corresponding to a specific subtype/dimension: obsessive jealousy/obsessionality, depressive jealousy/self-esteem, separation anxiety-related jealousy/fear of loss, paranoid jealousy/suspiciousness, and sen- 
Table 1. Distribution of the Romantic Attachment Styles in Men and Women

\begin{tabular}{|c|c|c|c|c|}
\hline Attachment Style & Men & Women & $\chi^{2}$ & .071 \\
\hline \hline Secure & 31 & 30 & .559 & N.S. \\
\hline Preoccupied & 8 & 13 & 2.337 & N.S. \\
\hline Fearful-avoidant & 4 & 6 & N.S. \\
\hline Dismissing & 4 & 4 & N.S. \\
\hline
\end{tabular}

sitivity-related jealousy/interpersonal sensitivity. The subtypes/dimensions were conceptualized as follows:

- Obsessive jealousy/obsessionality: characterized by involuntary feelings of jealousy which the individual is well aware must be excessive and unrealistic, but must struggle a lot to suppress [12];

- Depressive jealousy/self-esteem: characterized by the sense of inadequacy and inferiority when compared with the partner, which results in the inability to trust his/her faithfulness and which makes unavoidable the potential betrayal with some distant rivals [42-44];

- Separation anxiety-related jealousy/fear of loss: characterized by the inability to accept the prospect of a loss which it is perceived to be unbearable. As a consequence, the relationship becomes a kind of dependence, with the subject constantly requiring the proximity of the partner and showing signs of distress when separated [1-3, 27];

- Paranoid jealousy/suspisciousness: characterized by extreme diffidence and suspicion, as well as interpretative and control behaviors towards the partner and any perceived rival, and also by the complete and often entirely undeserved mistrust of the partner who, despite showing signs of true devotion, is considered to be of poor morality [45];

- Sensitivity-related jealousy/interpersonal sensitivity: characterized by hypersensitivity towards the partner and excessive reactivity to external stimuli and situations; a close proximity is generally avoided, although highly desiderable, and non-familiar individuals or items are considered potentially aggressive, so that everything and everybody is subjected to a constant monitoring [46, 47].

Some probe questions determine whether specific areas/situations are applicable to the respondent: if the answer to the probe question is "no", the questions exploring that specific area are skipped. We invited all participants to focus on a relevant current or previous, if single, relationship. All single subjects referred that they had been involved in at least one relevant romantic relationship. The QUEGE proved to be acceptable and required 15 minutes on average to com- plete. In addition, it resulted to be a reliable and sensitive instrument to detect the five subtypes of jealousy in an Italian population [37-39].

\section{Statistical Analyses}

The distribution of the attachment styles was compared using the chi-square test. The correlations between the scales of the ECR and the QUEGE dimensions were analyzed using the non-parametric statistic Spearman's rho, because of the asymmetric distribution of the QUEGE scores. The scores of each dimension of the QUEGE were compared amongst the romantic attachment styles by means of the Kruskal-Wallis and Dunn tests. All statistical analyses were carried out using the Statistical Package for the Social Sciences, Version 12.01 (SPSS Inc. 2003).

\section{RESULTS}

The attachment styles were distributed amongst subjects as follows: secure $(\mathrm{N}=61)$, preoccupied $(\mathrm{N}=22)$, fearfulavoidant $(\mathrm{N}=9)$ and dismissing $(\mathrm{N}=8)$. Although there was no significant gender difference in the distribution of the attachment styles, preoccupied and fearful-avoidant patterns were more frequent in women (Table 1).

As shown in Table 2, each dimension of the QUEGE was significantly related to the anxiety scale of the ECR and to the coefficients of each attachment style. The following dimensions of the QUEGE, self-esteem, fear of loss and suspiciousness, were significantly related to the ECR avoidance scale, at variance with interpersonal sensitivity and obsessionality. When analyzing the mean scores of the QUEGE dimensions in each attachment style (Table 3), it emerged that the subjects with the preoccupied style showed significantly higher scores than those with the secure style on the obsessionality, interpersonal sensitivity and fear of loss dimensions. The fearful-avoidant subjects also reported significant higher scores on the fear of loss dimension of the QUEGE than secure individuals, and a trend towards higher, albeit not significant, values on all the other dimensions. The dismissing subjects showed statistically significant lower scores on the self-esteem QUEGE dimension, than secure

Table 2. Correlations Between the ECR Scales (Avoidance, Anxiety) and the QUEGE Dimensions (Self-Esteem, Suspiciousness, Obsessionality, Interpersonal Sensitivity, Fear of Loss)

\begin{tabular}{|c|c|c|c|c|c|}
\hline Spearman's rho & Self-esteem & Suspiciousness & Obsessionality & Interpersonal Sensitivity & Fear of Loss \\
\hline \hline Avoidance & $\mathrm{r}_{\mathrm{s}}=.302(\mathrm{p}=.009)$ & $\mathrm{r}_{\mathrm{s}}=.229(\mathrm{p}=.048)$ & $\mathrm{r}_{\mathrm{s}}=.089($ N.S. $)$ & $\mathrm{r}_{\mathrm{s}}=.179(\mathrm{~N} . \mathrm{S}$.) & $\mathrm{r}_{\mathrm{s}}=.311(\mathrm{p}=.007)$ \\
\hline Anxiety & $\mathrm{r}_{\mathrm{s}}=.437(\mathrm{p}=.000)$ & $\mathrm{r}_{\mathrm{s}}=.309(\mathrm{p}=.007)$ & $\mathrm{r}_{\mathrm{s}}=.583(\mathrm{p}=.000)$ & $\mathrm{r}_{\mathrm{s}}=.633(\mathrm{p}=.000)$ & $\mathrm{r}_{\mathrm{s}}=.577(\mathrm{p}=.000)$ \\
\hline
\end{tabular}


Table 3. Scores (mean \pm SD) of the QUEGE Dimensions in the Different Romantic Attachment Styles Results of the Kruskal-Wallis Test in Each QUEGE Dimension $\left(\chi^{2}\right.$ and $\left.p\right)$ and of the Dunn test for multiple comparisons $(Q$ and $p)$

\begin{tabular}{|c|c|c|c|c|c|c|}
\hline Attachment Style & $\mathbf{N}$ & $\begin{array}{c}\text { Self-esteem } \\
\chi^{2}=\mathbf{1 0 . 8 2}(\boldsymbol{p}=\mathbf{. 0 1 3})\end{array}$ & $\begin{array}{c}\text { Suspiciousness } \\
\chi^{2}=\mathbf{6 . 6 7 3} \\
(\boldsymbol{N} . \mathbf{S} .)\end{array}$ & $\begin{array}{c}\text { Obsessionality } \\
\chi^{2}=\mathbf{2 5 . 7 3} \\
(\boldsymbol{p}=\mathbf{0 0 0})\end{array}$ & $\begin{array}{c}\text { Interp. Sens. } \\
\chi^{2}=\mathbf{2 2 . 6 8} \\
(\boldsymbol{p}=. \mathbf{0 0 0})\end{array}$ & $\begin{array}{c}\text { Fear of Loss } \\
\chi^{2}=\mathbf{1 6 . 0 3} \\
(\boldsymbol{p}=. \mathbf{0 0 1})\end{array}$ \\
\hline \hline A-Secure & 61 & $4.21 \pm 3.46$ & $4.87 \pm 3.46$ & $5.74 \pm 4.41$ & $10.26 \pm 2.21$ & $8.96 \pm 1.49$ \\
\hline B Preoccupied & 21 & $7.95 \pm 4.97$ & $7.00 \pm 3.64$ & $10.52 \pm 2.73$ & $14.26 \pm 3.51$ & $11.42 \pm 2.83$ \\
\hline C-Fearf-avoid. & 10 & $8.20 \pm 7.12$ & $7.00 \pm 3.80$ & $8.60 \pm 4.39$ & $11.60 \pm 2.07$ & $12.20 \pm 3.77$ \\
\hline D-dismissing & 8 & $5.75 \pm 4.50$ & $3.50 \pm 5.00$ & $3.00 \pm 4.00$ & $7.25 \pm 1.89$ & $9.75 \pm 2.06$ \\
\hline TOTAL & 100 & $5.51 \pm 4.48$ & $5.48 \pm 3.70$ & $7.00 \pm 4.56$ & $11.36 \pm 3.07$ & $9.84 \pm 2.41$ \\
\hline
\end{tabular}

Multiple comparisons:

Self-esteem: $Q_{A B}=2.96(p<.05)$

Obsessionality: $Q_{A B}=4.66(p<.01) ; Q_{B D}=3.23(p<.01)$

Interpersonal Sensitivity: $Q_{A B}=4.75(p<.01) ; Q_{B D}=2.27(p<.05)$

Fear of loss: $Q_{A B}=3.58(p<.01) ; Q_{A C}=2.39(p<.05)$

individuals, and a trend towards a higher fear of loss which, however, did not reach the statistical significance.

\section{DISCUSSION}

The present study explored the possible correlation between the scales of romantic attachment, assessed by means of the ECR, and five dimensions of jealousy derived from a specific questionnaire (QUEGE). The results showed that the ECR anxiety scale was significantly and positively related to all QUEGE dimensions, while the ECR avoidance scale was related only to the self-esteem, fear of loss and suspiciousness dimensions. Taken together, these findings suggest that the two phenomena, attachment and jealousy, are intertwined, as already reported [14-17, 30, 34]. However, the originality of our study was that we showed the presence of relationships with specific jealousy features possibly related to psychological dimensions rather to jealousy subtypes.

Interestingly, the analysis of the scores of the QUEGE dimensions in each attachment styles revealed some peculiarities. The subjects with the preoccupied style of romantic attachment, when compared with those with the secure style, had higher scores on different dimensions of jealousy, in particular obsessionality, fear of loss and interpersonal sensitivity. This is not surprising, since the three dimensions are strictly related in their meaning and, perhaps, emerge from a common anxious substrate. Preoccupied individuals had high, albeit not significant, score on the suspiciousness and self-esteem dimensions: this might be explained by their negative model of the self that would provoke their feeling of inadequacy, so that they consider the betrayal unavoidable [48]. The subjects with the fearful-avoidant romantic attachment style reported higher scores than secure individuals on the fear of loss dimension, and a trend towards lower scores on all the other dimensions. These findings suggest that preoccupied and fearful-avoidant subjects share high levels of anxiety. Dismissing subjects reported lower scores than secure individuals on the self-esteem dimension, probably because of their positive model of the self: this is consistent with the low levels of anxiety typical of these subjects.
On the contrary, they had high score, that however was not statistically significant, on the fear of loss dimension. Therefore, it might be that just the fear of losing the partner would be the "core" structure of the jealousy phenomenon that, in some individuals, may beget the obsessive thinking of a possible betrayal, and provoke the consequent monitoring of the partner.

The main bias of the present study is that the number of the subjects belonging to the different styles of romantic attachment was not the same, in any case, the distribution of the styles in our sample reflects that already reported by others [49-52]. In addition, the small sizes of some subgroups might limit the validity of statistical analyses and generalizability of our findings. However, our sample may be considered original, as all the subjects were not selected amongst students, as it is often the case [15, 53-59], although still not epidemiologically- based and recruited in two different environments: in any case, the two groups were quite similar and no difference in all tested variables/characteristics was detected.

\section{CONCLUSION}

In conclusion, the findings of the present study, while showing that the ECR scales and the QUEGE dimensions are highly related, suggest that different attachment styles may explain qualitative individual features of jealousy, at least in normal subjects. Since the fear of losing the partner resulted to be a common feature of preoccupied, fearful-avoidant and dismissing individuals, although in this last case the statistical significance was not reached perhaps for the small number of subjects, it is concluded that it might represent the "organizer" of the jealousy phenomenon. In addition, as these attachment styles have been linked to the development of psychopathology [9, 29, 32, 38, 60], this might explain the vulnerability of some jealousy subjects to cross the border between normal and pathological conditions that may reach extreme levels of severity. In the light of the present findings, it would be interesting to replicate this study in individuals suffering from pathological jealousy. 


\section{LIST OF ABBREVIATIONS}

$\begin{array}{lll}\text { QUEGE } & = & \text { Questionario della Gelosia } \\ \text { ECR } & = & \begin{array}{l}\text { Experiences in Close Relationships } \\ \text { questionnaire }\end{array}\end{array}$

\section{REFERENCES}

[1] Bowlby J. Attachment and Loss: Attachment. New York, NY: Basic Books 1969.

[2] Bowlby J. Attachment and Loss. Separation: Anxiety and Anger. New York, NY: Basic Books 1973.

[3] Bowlby J. Attachment and Loss: Loss, Sadness and Depression. New York, NY: Basic Books 1980.

[4] Ainsworth MDS, Blehar MC, WatersE, Wall S. Patterns of Attachment: Assessed in the Strange Situation and at Home. Hillsdale, NJ. Erlbaum, Inc. 1978

[5] Bifulco A, Moran PM, Ball C, Lillie A. Adult attachment style. II. Its relationship to psychosocial depressive-vulnerability. Soc Psychiatry Psychiatr Epidemiol 2002; 37: 60-7.

[6] Klohnen EC, Bera SJ. Behavioral and experiential patterns of avoidantly and securely attached women across adulthood: a 31year longitudinal perspective. J Pers Soc Psychol 1998; 74: 211-23.

[7] Waters E, Merrick S, Treboux D, Crowell J, Albersheim L. Attachment security in infancy and early adulthood: a twenty-year longitudinal study. Child Dev 2000, 71: 684-9.

[8] Hazan C, Shaver PR. Romantic love conceptualized as an attachment process. J Pers Soc Psychol 1987; 28: 511-24.

[9] Sharpsteen DJ, Kirkpatrick LA. Romantic jealousy and adult romantic attachment. J Pers Soc Psychol 1997; 72: 627-40.

[10] Mullen PE. Jealousy: the pathology of passion. Br J Psychiatry 1991; 158: 593-601.

[11] Tarrier N, Beckett R, Harwood S, Bishay N. Morbid jealousy: a review and cognitive-behavioural formulation. $\mathrm{Br} \mathrm{J}$ Psychiatry 1990; 157: 319-26.

[12] Parker G, Barrett E. Morbid jealousy as a variant of obsessivecompulsive disorder. Aust N Z J Psychiatry 1997; 31: 133-8.

[13] Buss DM, Haselton M. The evolution of jealousy. Trends Cogn Sci 2005; 9: 506-7.

[14] Salovey P. The psychology of jealousy and envy. New York: Guilford Press 1991, pp. 3-29.

[15] Mathes EW. Jealousy and romantic love: a longitudinal study. Psychol Rep 1986 ; 58: 885-6.

[16] Sommers Van P. Jealousy. New York: Penguin Books 1988.

[17] Sheets VL, Fredendall LL, Claypool HM. Jealousy evocation, partner reassurance, and relationship stability: an exploration of the potential benefits of jealousy. Evol Hum Behav 1997; 18: 387-402.

[18] Grossman KE, Grossman K. Attachment Across the Life Cycle. London, England: Routledge Press 1991.

[19] Bartholomew K, Horowitz LM. Attachment styles among young adults: a test of a four-category model. J Pers Soc Psychol 1991; 61: 226-44.

[20] Allen JP, Hauser ST, Borman-Spurrell E. Attachment theory as a framework for understanding sequelae of severe adolescent psychopathology: an 11-year follow-up study. J Consult Clin Psychol 1996; 64: 254-63.

[21] Amini F, Lewis T, Lannon L, et al. Affect, attachment, memory: contributions toward psychobiologic integration. Psychiatry 1996; 59: 213-39.

[22] Goldberg D. Vulnerability, destabilization and restitution in anxious depression. Acta Psychiatr Scand 2003; 418: 81-2.

[23] Troisi A, D'Argenio A. The relationship between anger and depression in a clinical sample of young men: the role of insecure attachment. J Affect Disord 2004; 79: 269-72.

[24] Feeney JA. Implications of attachment style for patterns of health and illness. Child Care Health Develop 2000; 2: 277-88.

[25] Eberhart NK, Hammen CL. Interpersonal predictors of stress generation. Pers Soc Psychol Bull 2009; 35: 544-56.

[26] Maunder RG, Hunter JJ. Attachment relationships as determinants of physical health. J Am Acad Psychoanal Dyn Psychiatry 2008; 36: 11-32.

[27] Brennan KA, Clark CL, Shaver PR. Self-Report Measurement of Adult Attachment: An Integrative Overview, Attachment Theory and Close Relationships. New York: Guilford Press 1998; pp. 4676.
[28] Radecki-Bush C, Farrell AD, Bush JI. Predicting jealous responses: The influence of adult attachment and depression on threat appraisal. J Soc Pers Relat 1993; 10: 569-88.

[29] Buunk BP. Personality, birth order and attachment styles as related to various types of jealousy. Pers Individ Dif 1997; 23: 997-1006.

[30] Guerrero LK. Attachment-style differences in the experience and expression of romantic jealousy. Pers Relat 1998; 5: 273-91.

[31] Brumbaugh CC, Fraley RC. Transference and attachment: how do attachment patterns get carried forward from one relationship to the next? Pers Soc Psychol Bull 2006; 2: 552-60.

[32] Simpson JA, Collins WA, Tran S, Haydon KC. Attachment and the experience and expression of emotions in romantic relationships: a developmental perspective. J Pers Soc Psychol 2007; 92: 355-67.

[33] Levy KN, Kelly KM. Sex differences in jealousy. A matter of evolution or attachment history? In: Mikulincer M, Goodman GS, Eds. Dynamics of romantic love: attachment, caregiving, and sex, New York: Guilford Press 2006; pp. 128-14.

[34] Rydell RJ, Bringle RG. Differentiating reactive and suspicious jealousy. Soc Behav Pers 2007; 35(8):1099-114.

[35] Paul L, Foss MA, Galloway J. Sexual jealousy in young men and women. Aggress Behav 1993; 19: 401-20.

[36] Mullen PE, Martin J. Jealousy: A community study. Br J Psychiatry $1993 ; 164: 35-43$.

[37] Marazziti D, Sbrana A, Rucci P, et al. Consoli G, Catena Dell'Osso M. Heterogeneity of the jealousy phenomenon in the general population: An Italian study. CNS Spectr 2010; 15: 19-24.

[38] Marazziti D, Di Nasso E, Masala I, et al. Normal and obsessional jealousy: A study of a population of young adults. Eur Psychiatry 2003; 18: 106-11.

[39] Sbrana A, Gonnelli C, Raimondi F, Doria MR, Mungai F, Ravani L. Sottotipizzazione della gelosia: indagine preliminare. Italian J Psychopathol 2004; 10: 91.

[40] First MB, Spitzer RL, Gibbon M, Williams JBW. Structured Clinical Interview for DSM-IV Axis I disorders - Patient Edition (SCIDI/P, Version 2.0). New York, NY: Biometrics Research Department, New York State Psychiatric Institute. 1995.

[41] Picardi A, Vermigli P, Toni A, D’amico R, Bitetti D, Pasquini P. Il questionario «Experience in Close Relationships» (ECR) per la valutazione dell'attaccamento negli adulti: ampliamento delle evidenze di validità per la versione italiana. Italian J Psychopathol 2002; 8: 282-94.

[42] Maggini C, Lensi P. Gelosia e depressione. Riv Sper Freniatria 1995; 119: 240-54

[43] De Steno D, Valdesolo P, Bartlett MY. Jealousy and the threatened self: getting the heart of the green-eyed monster. J Pers Soc Psycol 2006; 91: 626-41.

[44] Maggini C, Lundgren E, Leuci E. Jealous love and morbid jealousy. Acta Biomed 2006; 77: 137-46.

[45] Catalano-Nobili C, Cerquetelli G. Psicologia e psicopatologia della gelosia. Riv Neuropsichiatria 1953; 13: 213-48.

[46] Lagache D. Le jalousie amoureuse. Paris: Presses Universitaires de France 1947.

[47] Borel J. Les psychoses passionelles. Paris: L'Expansion Scientifique Francaise 1952.

[48] Allen ES, Baucom DH. Adult attachment and patterns of extradyadic involvement. Fam Process 2004, 43: 467-88.

[49] Mickelson KD, Kessler RC, Shaker PR. Adult attachment in nationally representative sample. J Pers Soc Psycol 1997; 73: 1092-106.

[50] Gjerde PF, Onishi M, Carlson KS. Personality characteristics associated with romantic attachment: a comparison of interview and self-report methologies. Pers Soc Psychol Bull 2004; 30: 1402-15.

[51] Marazziti D, Dell'Osso B, Catena Dell'Osso M, et al. Romantic attachment in patients with mood and anxiety disorders. CNS Spectr 2007; 12: 751-6.

[52] Riggs GA, Paulson A, Tunnell E, Sahl G, Atkinson HL, Ross CA Attachment, personality, and psychopathology among adult patients: self-reported romantic attachment style versus adult attachment interview states of mind. Develop Psychopathol 2007; 19: 263-9.

[53] Mathes EW, Roterr MP, Joerger SM. A convergence validity study of six jealousy scales. Psychol Rep 1982; 50: 1143-7.

[54] Buunk B, Falus G, Buss DM. Romantic jealousy and romantic envy: a seven nation study. J Cross-Cult Psychol 1985; 16: 423-46. 
[55] Buss DM. Sex differences in human mate preferences: Evolutionary hypotheses tested in 37 cultures. Behav Brain Sci 1989; 12: 149.

[56] Buss DM, Larsen RJ, Westen D, Semmelroth J. Sex differences in jealousy: Evolution, physiology, and psychology. Psychol Sci 1992; 3: 251-5.

[57] Michael A, Mirza S, Mirza KAH, Babu VS, Vithayathil E. Morbid jealousy in alcoholism. Br J Psychiatry 1995; 167: 668-72.
[58] Buunk BP, Angleitner A, Oubaid V, Buss DM. Sex differences in jealousy in evolutionary and cultural perspective: Tests from the Nederlands, Germany and the United States. Psychol Science 1996; 7: 359-63.

[59] Pines AM, Friedman A. Gender differences in romantic jealousy. J Soc Psychol 1997; 138: 54-71.

[60] Marazziti D, Rucci P, Di Nasso E, et al. Jealousy and subthreshold psychopathology: a serotonergic link. Neuropsychobiology 2003; 47: $12-6$

Received: November 25, 2009

(C) Marazziti et al.; Licensee Bentham Open.

This is an open access article licensed under the terms of the Creative Commons Attribution Non-Commercial License (http://creativecommons.org/licenses/by-nc/3.0/) which permits unrestricted, non-commercial use, distribution and reproduction in any medium, provided the work is properly cited. 